\title{
Complementing chronic frailty assessment at hospital admission with an electronic frailty index (FI-Laboratory) comprising routine blood test results
}

\author{
Hugh Logan Ellis MBBchir, Bettina Wan MBBS, Michael Yeung MBBS, Arshad Rather MBBS, \\ Imran Mannan MBBS, Catherine Bond MBBS, Catherine Harvey MBBS, Nadia Raja MBBS, \\ Peter Dutey-Magni PhD, Kenneth Rockwood MD MPA, Daniel Davis MBBS PhD, Samuel D. Searle MD
}

Cite as: CMAJ 2020 January 6;192:E3-8. doi: 10.1503/cmaj.190952

\begin{abstract}
BACKGROUND: Acutely ill and frail older adults have complex social and health care needs. It is important to understand how this complexity affects acute outcomes for admission to hospital. We validated a frailty index using routine admission laboratory tests with outcomes after patients were admitted to hospital.
\end{abstract}

METHODS: In a prospective cohort of older adults admitted to a large tertiary hospital in the United Kingdom, we created a frailty index from routine admission laboratory investigations (FI-Laboratory) linked to data comprising hospital outcomes. We evaluated the association between the FI-Laboratory and total days spent in hospital, discharge to a higher level of care, readmission and mortality.

RESULTS: Of 2552 admissions among 1750 older adults, we were able to generate FI-Laboratory values for 2254 admissions $(88.3 \%$ of the cohort). More than half of admitted patients were women $(55.3 \%)$ and the mean age was 84.6 (SD 14.0) years. We found that the FILaboratory correlated weakly with the Clinical Frailty Scale (CFS; $r^{2}=0.09$ ). An increase in the CFS and the equivalent of 3 additional abnormal laboratory test results in the FI-Laboratory, respectively, were associated with an increased proportion of inpatient days (rate ratios [RRs] 1.43, 95\% confidence interval [Cl]
$1.35-1.52$; and $1.47,95 \% \mathrm{Cl} 1.41-1.54)$, discharge to a higher level of care (odd ratios [ORs] 1.39, 95\% Cl 1.27-1.52; and $1.30,95 \% \mathrm{Cl} 1.16-1.47)$ and increased readmission rate (hazard ratios [HRs] $1.26,95 \% \mathrm{Cl} 1.17-1.37$; and $1.18,95 \% \mathrm{Cl}$ 1.11-1.26). Increases in the CFS and FILaboratory were associated with increased mortality HRs of $1.39(95 \% \mathrm{Cl}$ $1.28-1.51)$ and 1.45 (95\% Cl 1.37-1.54), respectively.

INTERPRETATION: We determined that FILaboratory, distinct from baseline frailty, could be used to predict risk of many adverse outcomes. The score is therefore a useful way to quantify the degree of acute illness in frail older adults.
$\mathbf{F}$

rail older adults have complex health and social care needs, and their functional abilities often decompensate in the face of acute illness. ${ }^{1}$ Adverse events occur in the short term (e.g., increased length of stay or hospital complications) ${ }^{2}$ and long term (e.g., readmission or death). ${ }^{3,4}$ One approach to quantifying frailty-associated risk has been to consider the accumulation of health deficits, as operationalized in the Frailty Index. ${ }^{5}$ This too is well-established in community samples; however, the extent to which these risk prediction tools can be translated in the acute setting where chronic and acute issues co-exist is unclear. Understanding how to measure accumulated deficits in frail patients presenting with acute illness would be an important step toward identifying patients who require targeted interventions such as those that maximize physical and cognitive function, ${ }^{6}$ or patients with many active health conditions.

Recent studies have used laboratory investigations combined as a frailty index (the Fl-Laboratory) to identify incipient frailty states that might increase risk of adverse outcomes from clinically detectable frailty. ${ }^{7-14}$ Adapted from animal studies, ${ }^{15}$ the human FI-Laboratory was developed and used in communitydwelling populations ${ }^{9,13,14,16-18}$ and in older adults in institutional 
care. ${ }^{8,19}$ The FI-Laboratory correlates with clinical frailty and enhances prediction of mortality, institutionalization and physician visits. ${ }^{13,20,21}$ Moreover, Fl-Laboratory scores contribute additional quantification of risk over and above clinical assessments of frailty. ${ }^{8-10,22,23}$ In the acute setting, where a range of laboratory investigations are routinely undertaken and readily available in electronic health records, creating an Fl-Laboratory captures the number of deficits on presentation in a standardized way. Initial studies among patients with trauma found that a high admission FI-Laboratory, in isolation, predicted a less favourable discharge location and mortality. ${ }^{23-25}$

If identifying the severity of illness of patients who are frail at presentation to hospital is important for the early care plan, ${ }^{6,26}$ then the FI-Laboratory may be a plausible "front door" tool that could inform potential interventions that may include management escalation, specific treatment paths, implementation of comprehensive geriatric assessments ${ }^{27}$ and admission to "senior-friendly" units. ${ }^{28}$ We evaluated the association of Fl-Laboratory, created at admission with common laboratory tests, with clinical frailty in relation to short-term outcomes (i.e., length of stay, a higher level of care upon discharge and in-hospital mortality) and long-term outcomes (i.e.,overall mortality, mortality after discharge and readmission).

\section{Methods}

\section{Study design and participants}

Between April 2015 and January 2017, consecutive admissions to the acute geriatric medicine service at a single tertiary hospital (University College Hospital, London, United Kingdom) were evaluated by a specialist geriatrician. This included assessments for dementia, delirium, falls and frailty during the first 24 hours of their admission ( $7 \mathrm{~d} / \mathrm{wk}$ ). We excluded hospital admissions shorter than 24 hours.

We used 2 summary measures quantifying chronic and acute health states, respectively. Chronic health status (physician estimate of baseline state 2 weeks before admission) was assessed using the Clinical Frailty Scale (CFS), ${ }^{29}$ scored from 1 (very fit) to 9 (terminally ill), with 5 representing "mildly frail." Acute health status was assessed through a laboratory frailty index (FI-Laboratory) created using a standard procedure. ${ }^{5,13}$ Source data for FI-Laboratory items came from the most common laboratory tests that are routinely undertaken for clinical investigations within the first 72 hours of admission and that further satisfied established criteria for creating a frailty index based on deficit accumulation (i.e., abnormalities in results for laboratory tests increase with age; abnormal values are associated with worse health status; and the abnormality does not saturate in the study population, e.g., it is present in $>80 \%$ of people by age $80 \mathrm{yr}$ ). This resulted in 27 items (Appendix 1, available at www.cmaj.ca/lookup/suppl/doi:10.1503/cmaj.190952/-/ DC1). We scored items as normal or abnormal based on local reference ranges. We obtained a score for FI-Laboratory by calculating the proportion of abnormal results from the total number of tests ordered. For example, if a patient had 9 abnormal test results from the 27 items, this would result in an FI-Laboratory score of 0.33 (9/27). Consistent with a previously published study on the creation and validation of an alternate FI-Laboratory, we required at least $70 \%$ or, in this instance, 19 of the 27 items to have been measured to generate a valid FI-Laboratory score. ${ }^{13}$ We also conducted sensitivity analyses in which an alternate FI-Laboratory was created with missing results scored as " 0 ."

\section{Outcomes and statistical analysis}

We considered 4 outcomes. First, total days in hospital from all admissions to hospital during the study period, analyzed as a count, with follow-up time as an offset (both inpatient and outpatient days, up to $21 \mathrm{mo}$ ). We analyzed this outcome using negative binomial regression. We did not include participants if they died during their index admission.

Our second outcome was discharge to a higher level of care, which we defined as in-hospital death or discharge to a location that would provide a higher level of care compared with the admitting location. We considered the highest level-of-care location to be another hospital, followed by nursing home, residential care home and, finally, the lowest level of care, a personal community dwelling ("home"). A patient admitted to hospital from their own home in the community and discharged to the same location would not have been discharged to a higher level of care. If they were discharged to a residential care home, nursing home, another hospital or died in hospital, they would have been considered to have been discharged to a higher level of care. We analyzed this binary outcome using logistic regression and clustered by patient identifier (ID).

Third, we investigated readmission to hospital within the study enrolment period (April 2015 to January 2017). All followup time was right censored at death or on the last day of study enrolment (21 mo). We conducted the analysis using Cox regression and clustered by patient ID because some participants had multiple presentations. ${ }^{4}$

Finally, we considered overall mortality from the date of admission to hospital to Dec. 11, 2018 (44 mo). We used a proportional Cox hazard model, right censored by readmission. We also used a sensitivity analysis to investigate mortality using index admission to Dec. 11, 2018. To account for competing risks, we analyzed a composite outcome of death or readmission to hospital, right censored on the last day of enrolment. We ascertained mortality through statutory reporting procedures (notifications to the hospital from the local register office).

We described the validity of the Fl-Laboratory based on its distribution, relation, 99th percentile and correlation with the CFS (Appendix 1). In addition to age (years) and sex (male/ female) co-variates, as assessed by the attending geriatricians within the first 24 hours of the patient's arrival on the acute care inpatient ward, we also used CFS (as a continuous measure), presence of dementia (yes/no), presence of delirium (yes/ no), a history of falls (yes/no) and residence at admission (except where the outcome was "discharge to a higher level of care"). We used Python $3.6^{30}$ and Stata 15 (StataCorp)-to perform the analyses. 
Table 1: Demographic characteristics of the study population

No. (\%) of included patients*

No. $(\%)$ of excluded patients*

\begin{tabular}{|c|c|c|c|}
\hline Characteristic & $n=2254$ & $n=298 \dagger$ & $n=233 \ddagger$ \\
\hline Age, yr; mean \pm SD & $84.8 \pm 14.0$ & $85.1 \pm 13.6$ & $84.9 \pm 7.5$ \\
\hline Sex, female & $1246(55.3)$ & $180(60.4)$ & $135(57.9)$ \\
\hline With dementia & $1127(50.0)$ & $160(53.7)$ & $99(42.5)$ \\
\hline With delirium & $770(34.2)$ & $83(27.9)$ & $30(12.9)$ \\
\hline With a history of falls & $976(43.3)$ & $137(46.0)$ & $84(36.1)$ \\
\hline FI-Laboratory score $(95 \% \mathrm{Cl})$ & $0.3(0.2-0.4)$ & - & $0.2(0.1-0.3)$ \\
\hline $\begin{array}{l}\text { Admissions per patient during study } \\
\text { enrolment ( } 21 \mathrm{mo}) \text {, mean } \pm \text { SD }\end{array}$ & $2.2 \pm 1.7$ & $2.1 \pm 1.7$ & - \\
\hline Length of stay, $\mathrm{d}$; median \pm IQR & $6(1-11)$ & $4(1-7)$ & - \\
\hline Died & $1266(56.4)$ & $143(48.6)$ & $104(44.6)$ \\
\hline Admitted from home & $1990(88.7)$ & $261(88.8)$ & $207(88.8)$ \\
\hline \multicolumn{4}{|l|}{ Discharged to: } \\
\hline Home & $1682(75.0)$ & $227(77.2)$ & $207(88.8)$ \\
\hline Residential care home & $43(1.9)$ & $8(2.7)$ & $2(0.9)$ \\
\hline Nursing care home & $177(7.9)$ & $24(8.2)$ & $8(3.4)$ \\
\hline Hospital transfer & $157(7.0)$ & $18(6.1)$ & $9(3.9)$ \\
\hline Died & $182(8.1)$ & $17(5.8)$ & $6(2.6)$ \\
\hline Other & $2(0.1)$ & - & $1(0.4)$ \\
\hline \multicolumn{4}{|l|}{ Clinical Frailty Scale (CFS) } \\
\hline Very fit $(C F S=1)$ & $2(0.1)$ & $1(0.3)$ & - \\
\hline Well (CFS = 2) & $9(0.4)$ & - & $4(1.7)$ \\
\hline Managing well (CFS = 3) & $29(1.3)$ & $4(1.4)$ & $11(4.7)$ \\
\hline Vulnerable (CFS = 4) & $156(7.0)$ & $22(7.5)$ & $31(13.3)$ \\
\hline Mildly frail (CFS = 5) & $548(24.4)$ & $67(22.8)$ & $68(29.2)$ \\
\hline Moderately frail (CFS = 6) & $810(36.1)$ & $120(40.8)$ & $77(33.0)$ \\
\hline Severely frail $($ CFS $=7$ ) & $575(25.6)$ & $65(22.1)$ & $32(13.7)$ \\
\hline Very severely frail (CFS = 8) & $91(4.1)$ & $9(3.1)$ & $9(3.9)$ \\
\hline Terminally ill (CFS = 9) & $23(1.0)$ & $6(2.0)$ & $1(0.4)$ \\
\hline
\end{tabular}

\section{Ethics approval}

These analyses were conducted as part of a service evaluation project and individual consent was not necessary as determined by the NHS Health Research Authority.

\section{Results}

In total, 2552 separate admissions were recorded for 1750 patients ( $31 \%$ had more than 1 admission). We were able to generate $\mathrm{FI}$-Laboratory values for 2254 admissions (88.3\%; 1580 individual patients, 90.3\%). The average age was 84.8 (SD 14.0) yr, and $55.3 \%$ of the patients were women (Table 1; Appendix 2, available at www.cmaj.ca/lookup/suppl/doi:10.1503/cmaj. 190952/-/DC1).

The 99th percentile of the FI-Laboratory was 0.63. The $\mathrm{FI}$-Laboratory correlated weakly with the CFS $\left(r^{2}=0.09, p<0.01\right)$. For each of the 4 clinical outcomes considered, independent associations for both FI-Laboratory and the CFS were evident (Table 2).

The average length of hospital admission was 12.5 days. Higher CFS and FI-Laboratory scores were associated with more days in hospital during the study period, even after accounting for age, sex and delirium or falls on presentation to hospital (Table 2). An increase in the CFS was associated with an increase in admission days (rate ratio [RR] 1.43, 95\% confidence interval [CI] 1.35-1.52). 
Table 2: Univariable and multivariable models for total in-hospital days with follow-up time as an offset, logistic regression model for discharge to a higher level of care compared with admission location, and Cox regression models for readmission and for mortality

\begin{tabular}{|c|c|c|c|c|c|c|c|c|}
\hline \multirow[b]{3}{*}{ Variable } & \multicolumn{2}{|c|}{$\begin{array}{c}\text { Inpatient days with follow-up } \\
\text { as offset }\end{array}$} & \multicolumn{2}{|c|}{$\begin{array}{l}\text { Discharge to a higher level of } \\
\text { care }\end{array}$} & \multicolumn{2}{|c|}{ Readmission } & \multicolumn{2}{|c|}{ Mortality } \\
\hline & \multicolumn{2}{|c|}{ Rate ratio $(95 \% \mathrm{CI})$} & \multicolumn{2}{|c|}{ OR (95\% CI) } & \multicolumn{2}{|c|}{ HR $(95 \% \mathrm{CI})$} & \multicolumn{2}{|c|}{ HR (95\% CI) } \\
\hline & $\begin{array}{l}\text { Univariable } \\
\text { model }\end{array}$ & $\begin{array}{l}\text { Multivariable } \\
\text { model }\end{array}$ & $\begin{array}{l}\text { Univariable } \\
\text { model }\end{array}$ & $\begin{array}{l}\text { Multivariable } \\
\text { model }\end{array}$ & $\begin{array}{l}\text { Univariable } \\
\text { model }\end{array}$ & $\begin{array}{l}\text { Multivariable } \\
\text { model }\end{array}$ & $\begin{array}{l}\text { Univariable } \\
\text { model }\end{array}$ & $\begin{array}{l}\text { Multivariable } \\
\text { model }\end{array}$ \\
\hline FI-Laboratory ${ }^{\star}$ & $1.61(1.54-1.69)$ & $1.47(1.41-1.54)$ & $1.40(1.29-1.53)$ & $1.39(1.27-1.52)$ & $1.20(1.12-1.28)$ & $1.18(1.11-1.26)$ & $1.51(1.43-1.60)$ & $1.45(1.37-1.54)$ \\
\hline CFS & $1.69(1.60-1.80)$ & $1.43(1.35-1.52)$ & $1.42(1.28-1.58)$ & $1.30(1.16-1.47)$ & $1.24(1.16-1.32)$ & $1.26(1.17-1.37)$ & $1.53(1.43-1.63)$ & $1.39(1.28-1.51)$ \\
\hline Age & $1.01(1.00-1.02)$ & $1.01(1.00-1.02)$ & $1.00(0.99-1.02)$ & $0.99(0.98-1.01)$ & $1.02(1.01-1.03)$ & $1.01(1.00-1.03)$ & $1.04(1.03-1.05)$ & $1.03(1.02-1.05)$ \\
\hline $\begin{array}{l}\text { Female sex (v. } \\
\text { male sex) }\end{array}$ & $0.62(0.55-0.71)$ & $0.66(0.59-0.75)$ & $0.90(0.73-1.12)$ & $0.94(0.75-1.19)$ & $0.91(0.76-1.09)$ & $0.89(0.74-1.06)$ & $0.76(0.67-0.87)$ & $0.74(0.64-0.86)$ \\
\hline Delirium & $2.57(2.25-2.93)$ & $1.71(1.50-1.97)$ & $1.88(1.52-2.32)$ & $1.38(1.07-1.77)$ & $1.01(0.86-1.18)$ & $0.91(0.76-1.09)$ & $1.67(1.46-1.91)$ & $1.29(1.10-1.52)$ \\
\hline Falls & $0.65(0.57-0.74)$ & $1.04(0.92-1.17)$ & $1.35(1.10-1.66)$ & $1.60(1.27-2.01)$ & $1.06(0.91-1.23)$ & $1.06(0.91-1.24)$ & $0.89(0.78-1.01)$ & $0.93(0.80-1.09)$ \\
\hline Dementia & $1.64(1.45-1.87)$ & $0.97(0.85-1.11)$ & $1.38(1.12-1.71)$ & $1.14(0.88-1.48)$ & $0.92(0.78-1.08)$ & $0.85(0.70-1.02)$ & $1.26(1.10-1.43)$ & $0.98(0.83-1.15)$ \\
\hline $\begin{array}{l}\text { Admitted from } \\
\text { own home }\end{array}$ & $1.56(1.47-1.64)$ & $1.24(1.08-1.37)$ & - & $-\quad-$ & $1.10(0.57-1.16)$ & $1.31(0.98-1.75)$ & $0.54(0.46-0.64)$ & $0.76(0.62-0.92)$ \\
\hline
\end{tabular}

Note: $\mathrm{CFS}=$ Clinical Frailty Scale, $\mathrm{Cl}=$ confidence interval, $\mathrm{FI}$-Laboratory = Frailty Index of common laboratory tests, $\mathrm{HR}=$ hazard ratio, $\mathrm{OR}=\mathrm{odds}$ ratio

${ }^{*} \mathrm{~A}$ change in $\mathrm{FI}$-Laboratory represents a 0.10 increase (3 deficits). Delirium, falls and dementia were ascertained on admission to hospital.

Each 0.10 ( 3 deficits) increase in the Fl-Laboratory was associated with an increase in admission days (RR $1.47,95 \% \mathrm{Cl} 1.41-1.54$ ).

A higher level of care was the destination in $17 \%$ of discharges. We found that higher CFS and FI-Laboratory were associated with being discharged to a higher level of care, with an odds ratio [OR] of $1.30(95 \% \mathrm{Cl} 1.16-1.47)$ for a 1-point increase in the CFS and 1.39 (95\% Cl 1.27-1.52) for a 0.10 increase in the FILaboratory (Table 2). A presentation of falls or delirium was also associated with being discharged to a higher level of care.

We identified 802 readmissions (Figure 1). We found that both a higher CFS and a higher FI-Laboratory score was associated with an increased readmission rate. Older age was also associated with an increased readmission rate (Table 2). A 0.10 increase in the FI-Laboratory was associated with a readmission hazard ratio [HR] of 1.18 (95\% $\mathrm{Cl} 1.11-1.26)$ (Figure 1B), whereas an additional point on the CFS had a HR of 1.26 (95\% Cl $1.17-$ 1.37) (Figure $1 \mathrm{~A}$ ).

More than half ( $n=1266,56.4 \%$ ) of the participants died during the follow-up period. A single point higher CFS and a 0.10 increase in the FI-Laboratory score were associated with increased risk of death (Table 2). Their HRs for mortality were 1.39 (95\% Cl 1.28-1.51) and $1.45(95 \% \mathrm{Cl} 1.37-1.54)$, respectively (Figure 2). Age (HR 1.03, 95\% Cl 1.02-1.05) and being female (HR $0.74,95 \% \mathrm{Cl} 0.64-0.86$ ) were also associated with mortality. We found that analysis of mortality based solely on incident admission did not significantly change the results (Appendix 1).

No interactions were evident between FI-Laboratory, CFS or age. In the sensitivity analysis in which missing laboratory results were assigned a value of " 0 " the results were unchanged (results not included). We found that results for mortality were unchanged only when taking into account index admission during the study period and were consistent with the results of the composite outcome model (Appendix 1).

\section{Interpretation}

Among older adults admitted to hospital, we determined that the FILaboratory score offers distinct, yet complementary, information to the chronic accumulation of deficits. It is associated with several adverse outcomes, in addition to those conferred by the CFS and to chronological age. We also found that the Fl-Laboratory score was associated with higher rates of readmission. Our findings suggest that the Fl-Laboratory score can usefully measure accumulated deficits in older adults who present to hospital with acute illness. The FILaboratory score combines features that both predispose to and precipitate acute illness. By quantifying both acute and chronic deficits, the score may draw attention to risk that is not apparent clinically.

We add to the body of evidence about the Fl-Laboratory - which has been studied in the acute care setting - by studying its performance prospectively in a population of older adults admitted to a general internal medicine ward, by examining a broad range of outcomes, and by including a clinical assessment of frailty in the analysis. A 2017 study involving patients aged 65 years and older found a clear relation with mortality and the acute FI-Laboratory score and frailty. ${ }^{22}$ In a 2019 follow-up study, these researchers reported that change in the FI-Laboratory score between admission to hospital and discharge was associated with mortality. ${ }^{24}$ In a Canadian study, 266 older patients with trauma were investigated by employing both an FI-Laboratory score and the CFS. ${ }^{23}$ In a univariable analysis, the authors found that the CFS was associated with more inpatient complications and the FI-Laboratory score was associated with adverse discharge destination. They did not report on the association of 

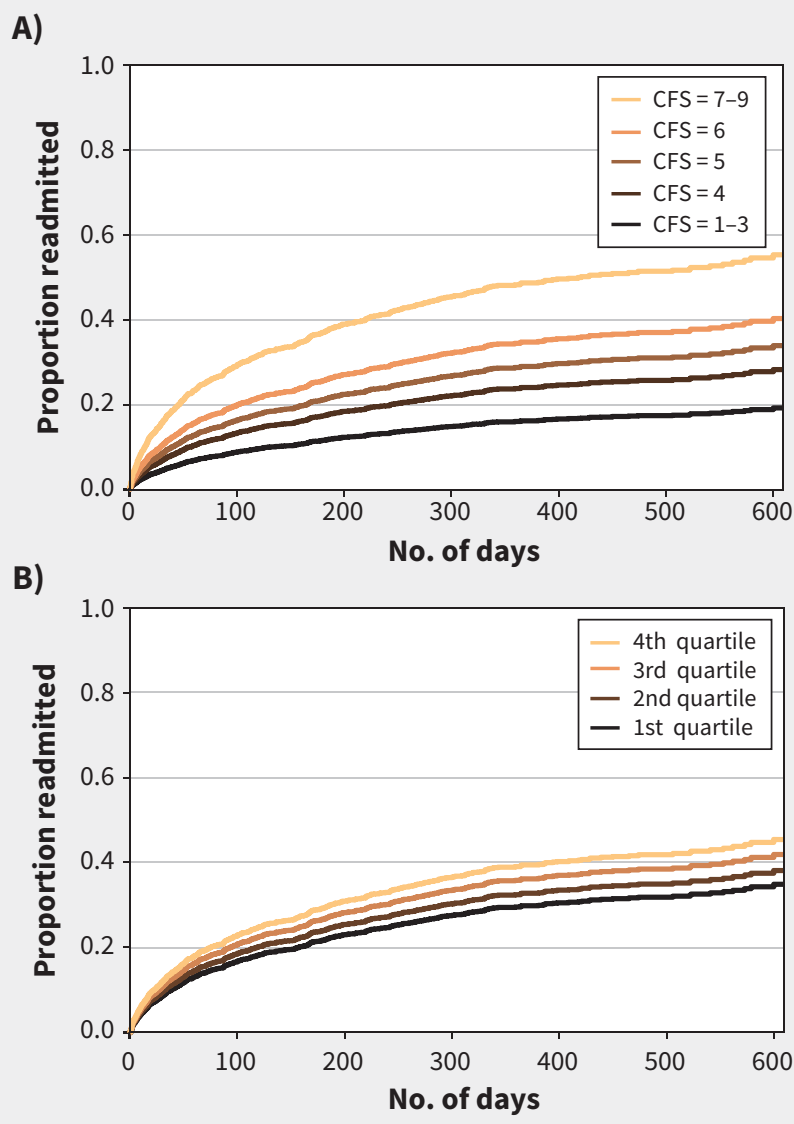

Figure 1: Proportion of participants who were readmitted to hospital calculated by using a multivariable Cox regression model for readmission adjusted up and down by hazard ratios from the A) CFS and B) FILaboratory. Curves use the multivariable Cox model with a participant age of 75 years, no dementia (0), male (0), no delirium (0), admitted from home (0), no history of falls (0), and either 8 abnormal laboratory values (Panel A) or a CFS of "6-Moderately Frail" (Panel B). Note: CFS = Clinal Frailty Scale, FI-Laboratory = Frailty Index of common laboratory tests.

inpatient complications with the Fl-Laboratory score. We found that the FI-Laboratory was associated with discharge location. We believe this may reflect our study's increased power; however, Cheung and colleagues ${ }^{23}$ included a trauma-specific severity measure in their multivariable analysis. In a 2017 study with a large general older population who presented to hospital, an acute FILaboratory score was associated with inpatient and postdischarge mortality; however, critically, the authors did not account for frailty beyond the $\mathrm{FI}$-Laboratory. ${ }^{25,31}$

\section{Limitations}

There are several limitations to our study. We conducted our study in a single centre. The Fl-Laboratory score, despite demonstrating properties consistent with other frailty indices, and including more items than other Fl-Laboratory studies, nevertheless included slightly fewer than the 30 items ${ }^{27}$ recommended. The Fl-Laboratory score was missing in $11.6 \%$ of the cases owing to insufficient laboratory investigation information. It is probable that the "intention to investigate" itself carries prognostic information, and those patients requiring fewer investigations are less likely to be frail. ${ }^{32}$ Our sensitivity analysis with an alternate operationalized FI-Laboratory score suggests that unordered

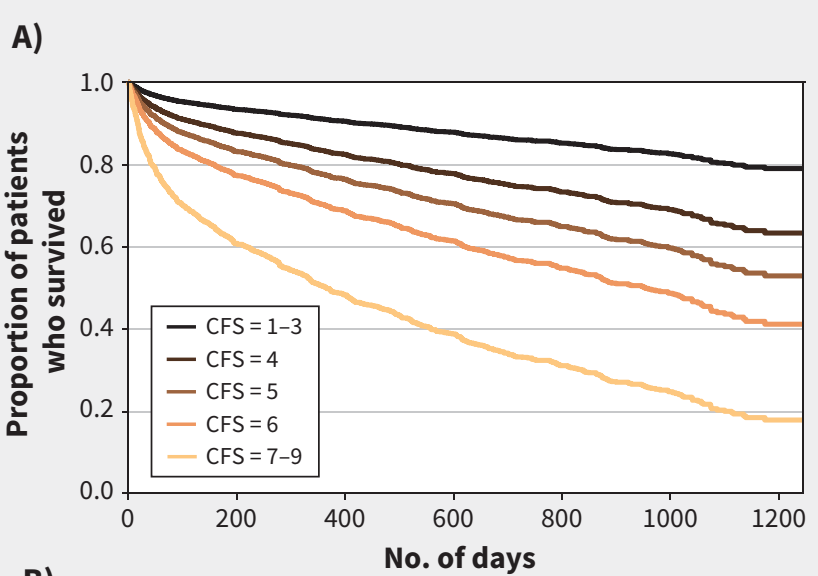

B)

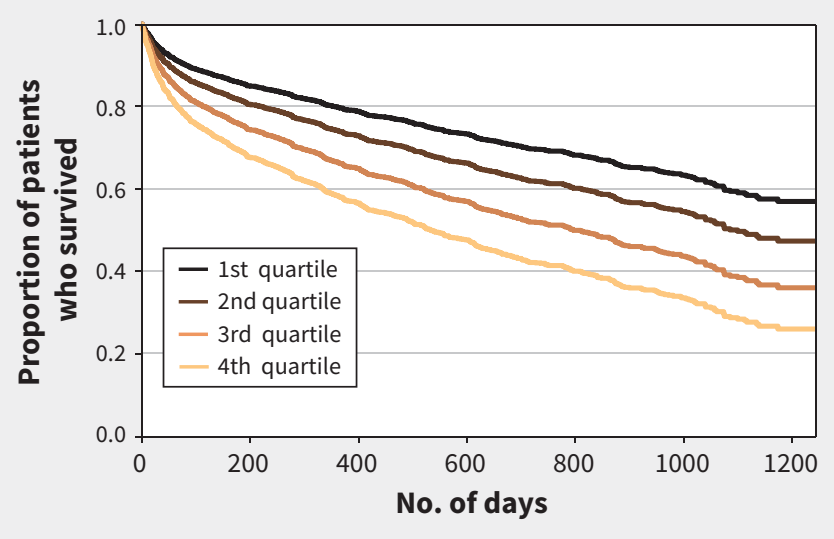

Figure 2: Kaplan-Meier curves adjusted by A) the hazard ratios of CFS scores and B) quartiles of the FI-Laboratory as estimated in the multivariable Cox model. Survival curves use the multivariable Cox model with a participant age of 75 years, no dementia (0), male (0), no delirium (0), admitted from home (0), no history of falls (0), and either 8 abnormal laboratory values (Panel A) or a CFS of "6-Moderately Frail" (Panel B). Note: CFS = Clinal Frailty Scale, FI-Laboratory = Frailty Index of common laboratory tests.

laboratory tests are likely to be normal. Finally, we censored death upon readmission. Although this is informative censoring, we are reassured that our findings held in relation to the FI-Laboratory and CFS when we analyzed mortality with index admission as well as with the composite outcome of death or readmission.

\section{Conclusion}

Assessing clinical frailty in the acute care setting is difficult. The FI-Laboratory can help to identify complex, acutely ill older adults at hospital admission who have accumulated multiple health deficits and are at an increased risk of adverse outcomes. However, whether its use results in improved clinical outcomes is not known. It also remains to be determined whether changes in the $\mathrm{Fl}$-Laboratory during hospital admission might add prognostic information during the course of a hospital stay, whether in relation to recovery or to a higher burden of frailty. These possibilities are motivating additional research by our group.

\section{References}

1. Clegg A, Young J, Iliffe S, et al. Frailty in elderly people. Lancet 2013;381:752-62.

2. Hubbard RE, Peel NM, Samanta M, et al. Frailty status at admission to hospital predicts multiple adverse outcomes. Age Ageing 2017;46:801-6. 
3. Bernabeu-Mora R, García-Guillamón G, Valera-Novella E, et al. Frailty is a predictive factor of readmission within 90 days of hospitalization for acute exacerbations of chronic obstructive pulmonary disease: a longitudinal study. Ther Adv Respir Dis 2017;11:383-92

4. Theou O, Squires E, Mallery K, et al. What do we know about frailty in the acute care setting? A scoping review. BMC Geriatr 2018;18:139. doi:10.1186/ s12877-018-0823-2.

5. Searle SD, Mitnitski A, Gahbauer EA, et al. A standard procedure for creating a frailty index. BMC Geriatr 2008;8:24

6. Gilbert T, Neuburger J, Kraindler J, et al. Development and validation of a Hospital Frailty Risk Score focusing on older people in acute care settings using electronic hospital records: an observational study. Lancet 2018;391:1775-82.

7. Al Saedi AA, Feehan J, Phu S, et al. Current and emerging biomarkers of frailty in the elderly. Clin Interv Aging 2019;14:389-98.

8. Rockwood K, Mcmillan Bsc M, Mitnitski A, et al. A frailty index based on common laboratory tests in comparison with a clinical frailty index for older adults in longterm care facilities. JAm Med Dir Assoc 2015;16:842-7.

9. Blodgett JM, Theou O, Howlett SE, et al. A frailty index from common clinical and laboratory tests predicts increased risk of death across the life course. GeroScience 2017;39:447-455.

10. Blodgett JM, Theou O, Howlett SE, et al. A frailty index based on laboratory deficits in community-dwelling men predicted their risk of adverse health outcomes. Age Ageing 2016;45:463-8.

11. Kane AE, Keller KM, Heinze-Milne S, et al. A Murine frailty index based on clinical and laboratory measurements: links between frailty and pro-inflammatory cytokines differ in a sex-specific manner. J Gerontol A Biol Sci Med Sci 2019;74:275-82.

12. Cardoso AL, Fernandes A, Aguilar-Pimentel JA, et al. Towards frailty biomarkers: Candidates from genes and pathways regulated in aging and age-related diseases. Ageing Res Rev 2018;47:214-77.

13. Howlett SE, Rockwood MRH, Mitnitski A, et al. Standard laboratory tests to identify older adults at increased risk of death. BMC Med 2014;12:171.

14. Bello GA, Lucchini RG, Teitelbaum SL, et al. Development of a physiological frailty index for the World Trade Center General Responder Cohort. Curr Gerontol Geriatr Res 2018; Feb 26:3725926.

15. Parks AL, Fang MC. Anticoagulation in older adults with multimorbidity. Clin Geriatr Med 2016;32:331-46.

16. King KE, Fillenbaum GG, Cohen HJ. A cumulative deficit laboratory test-based frailty index: personal and neighborhood associations. J Am Geriatr Soc 2017;65:1981-7.

17. Ma T, Cai J, Zhu Y-S, et al. Association between a frailty index based on common laboratory tests and QTc prolongation in older adults: the Rugao Longevity and Ageing Study. Clin Interv Aging 2018;13:797-804
18. Hao Q, Sun X, Yang M, et al. Prediction of mortality in Chinese very old people through the frailty index based on routine laboratory data. Sci Rep 2019;9:221. doi:10.1038/s41598-018-36569-9.

19. Yang M, Zhuo Y, Hu X, et al. Predictive validity of two frailty tools for mortality in Chinese nursing home residents: frailty index based on common laboratory tests (FILab) versus FRAIL-NH. Aging Clin Exp Res 2018;30:1445-52.

20. Blodgett JM, Theou O, Howlett SE, et al. A frailty index based on laboratory deficits in community-dwelling men predicted their risk of adverse health outcomes. Age Ageing 2016;45:463-8.

21. Yang M, Zhuo Y, Hu X, et al. Predictive validity of two frailty tools for mortality in Chinese nursing home residents: frailty index based on common laboratory tests (FILab) versus FRAIL-NH. Aging Clin Exp Res 2018;30:1445-52.

22. Ritt M, Jäger J, Ritt J, et al. Operationalizing a frailty index using routine blood and urine tests. Clin Interv Aging 2017;12:1029-40.

23. Cheung A, Haas B, Ringer TJ, et al. Canadian study of Health and Aging Clinical Frailty Scale: Does it predict adverse outcomes among geriatric trauma patients? J Am Coll Surg 2017;225:658-65.e3.

24. Jäger J, Sieber CC, Gaßmann K-G, et al. Changes of a frailty index based on common blood and urine tests during a hospital stay on geriatric wards predict 6-month and 1-year mortality in older people. Clin Interv Aging 2019;14:473-84.

25. Klausen $\mathrm{HH}$, Petersen J, Bandholm T, et al. Association between routine laboratory tests and long-term mortality among acutely admitted older medical patients: a cohort study. BMC Geriatr 2017;17:62.

26. Searle SD, Rockwood K. What proportion of older adults in hospital are frail? Lancet 2018;391:1751-2

27. Ellis G, Gardner M, Tsiachristas A, et al. Comprehensive geriatric assessment fo older adults admitted to hospital. Cochrane database Syst Rev 2017;(9):CD006211.

28. Landefeld CS, Palmer RM, Kresevic DM, et al. A randomized trial of care in a hospita medical unit especially designed to improve the functional outcomes of acutely ill older patients. N Engl J Med 1995;332:1338-44.

29. Rockwood K, Song X, MacKnight C, et al. A global clinical measure of fitness and frailty in elderly people. CMAJ 2005;173:489-95.

30. McKinney W. Data structures for statistical computing in Python. In: van der Walt S, Millman J, editors. Proceedings from the 9th Python in Science Conference; 2010 June 28-July 3; Austin (TX): SciPy 2010;2010:51-6.

31. Klausen HH, Petersen J, Bandholm T, et al. Erratum to: Association between routine laboratory tests and long-term mortality among acutely admitted older medical patients: a cohort study. BMC Geriatr 2017;17:67. doi:10.1186/s12877-017-0463-y.

32. Agniel D, Kohane IS, Weber GM. Biases in electronic health record data due to processes within the healthcare system: retrospective observational study [published erratum in BMJ 2018;363:k4416]. BMJ 2018;361:k1479.
Competing interests: Kenneth Rockwood asserted copyright of the Clinical Frailty Scale (CFS) through Dalhousie University, Halifax; the CFS is freely available for research, educational and use by not-for-profit health care. He is President, Chief Science Officer and founder of DGI Clinical. He has received personal fees for guest lectures and academic symposia from Cape Breton University; Centre de recherche institut universitaire de gériatrique de Montréal; The Jackson Laboratory, Bar Harbor, Maine; MouseAGE meeting, Rome, Italy; Frontotemporal Degeneration Treatment Study Group; and SunLife Insurance, Japan. $\mathrm{He}$ also received personal fees for attending an advisory board meeting at Lundbeck. No other competing interests were declared.

This article has been peer reviewed.

Affiliations: University College London Hospitals NHS Foundation Trust (Logan Ellis, Wan, Yeung, Rather, Mannan, Bond, Harvey, Raja, Davis); Institute of Health Informatics (DuteyMagni), UCL; MRC Unit for Lifelong Health and Ageing at UCL (Davis, Searle), London, UK; Division of Geriatric Medicine, Department of Medicine (Rockwood, Searle), Dalhousie University, Halifax, NS
Contributors: Samuel Searle, Daniel Davis and Kenneth Rockwood contributed substantially to the conception of the work. Samuel Searle and Hugh Logan Ellis analyzed the data for the work and wrote the original draft of the manuscript. Samuel Searle, Hugh Logan Ellis, Bettina Wan, Michael Yeung, Arshad Rather, Imran Mannan, Catherine Bond, Catherine Harvey and Nadia Raja were responsible for data curation. Samuel Searle, Daniel Davis, Peter DuteyMagni and Hugh Logan Ellis were responsible for methodology. All of the authors revised the manuscript critically for important intellectual content, gave final approval of the version to be published and agreed to be accountable for all aspects of the work.

Funding: Hugh Logan Ellis is supported by a UCLH CEO Clinical Research Fellowship. Kenneth Rockwood receives career support from the Dalhousie Medical Research Foundation as the Kathryn Allen Weldon Professor of Alzheimer Research, and research support through grants from the Canadian Frailty Network, the Nova Scotia Health Research Foundation, the Nova Scotia Health Authority Research Fund and the Fountain Family Innovation Fund of the QEII Health Sciences Centre Foundation. $\mathrm{He}$ is Associate Director of the Canadian Con- sortium on Neurodegeneration in Aging, which is funded by the Canadian Institutes of Health Research (CAN-137794). Daniel Davis is funded through a Wellcome Intermediate Clinical Fellowship (WT107467). Samuel Searle is supported with fellowship funding from the Dalhousie Medical Research Foundation, the Queen Elizabeth II Health Sciences Centre Foundation, as a Detweiler Travelling Fellow, and through the Canadian Frailty Network with an Interprofessional fellowship. The funders played no role in the writing of the manuscript.

Copyright: This is an Open Access article distributed in accordance with the terms of the Creative Commons Attribution (CC BY 4.0) licence, which permits others to distribute, remix, adapt and build upon this work, for commercial use, provided the original work is properly cited. See: http://creativecommons. org/licenses/by/4.0/.

Data sharing: The data sets used and/or analyzed during this study are available from the corresponding author on reasonable request.

Accepted: Nov. 8, 2019

Correspondence to: Samuel Searle, ssearle@ dal.ca 